\author{
I50 Jahre \\ Wissen für die Zukunft \\ (48) Oldenbourg Verlag
}





\title{
Humanressourcen- Management
}

\author{
von \\ Universitätsprofessor \\ Dr. Max Ringlstetter \\ und \\ Dr. Stephan Kaiser
}

Oldenbourg Verlag München 
Bibliografische Information der Deutschen Nationalbibliothek

Die Deutsche Nationalbibliothek verzeichnet diese Publikation in der Deutschen Nationalbibliografie; detaillierte bibliografische Daten sind im Internet über $<$ http://dnb.d-nb.de> abrufbar.

\author{
(c) 2008 Oldenbourg Wissenschaftsverlag GmbH \\ Rosenheimer Straße 145, D-81671 München \\ Telefon: (089) 45051-0 \\ oldenbourg.de
}

Das Werk einschließlich aller Abbildungen ist urheberrechtlich geschützt. Jede Verwertung außerhalb der Grenzen des Urheberrechtsgesetzes ist ohne Zustimmung des Verlages unzulässig und strafbar. Das gilt insbesondere für Vervielfältigungen, Übersetzungen, Mikroverfilmungen und die Einspeicherung und Bearbeitung in elektronischen Systemen.

Lektorat: Wirtschafts- und Sozialwissenschaften, wiso@oldenbourg.de Herstellung: Anna Grosser Coverentwurf: Kochan \& Partner, München Gedruckt auf säure- und chlorfreiem Papier Druck: Grafik + Druck, München Bindung: Thomas Buchbinderei GmbH, Augsburg

ISBN 978-3-486-58415-8 